\title{
La culture des sorghos fourragers â Madagascar Utilisation à contre-saison
}

\author{
par P. GRANIER et A. BIGOT
}

\begin{abstract}
RESUME
Les essais conduits par les auteurs ont mis en évidence l'intérêt présenté par les sorghos, tant en culture dérobée qu'en culture de contre saison. Leurs faibles exigences en eau et leur rendement élevé doivent permettre une meilleure utilisation des sols, l'inténsification de l'élevage (viande et lait) et partout où existent des sous-produits, tels les farines basses de riz et les tourteaux, la production d'animaux d'embouche tels que demandés en priorité par le commerce du bétail et de la boucherie malgaches.
\end{abstract}

\section{INTRODUCTION}

L'industrialisation à Madagascar de l'élevage bovin nécessite la production de fourrages abondants et de bonne valeur alimentaire. Dans de nombreuses régions d'élevage, les sorghos fourragers paraissent devoir jouer un rôle important dans cette industrialisation. Ce sont des plantes qui, en peu de temps d'occupation du sol, fournissent, même avec un approvisionnement en eau minime, en saison sèche, donc, lorsque les autres fourrages sont au repos, une quantité importante d'un fourrage que l'on peut utiliser en vert, en ensilage, avec les grains pâteux ou secs.

Actuellement, dans les régions tropicales, à côté de l'élevage extensif traditionnel, existe la possibilité de création d'unités d'embouche dans lesquelles le bétail peut être nourri avec les sous-produits qui existent sur place, et ne sont pas toujours valorisés (farine de riz, graines de coton, tourteaux divers, etc...).

A partir du moment où l'élevage s'industrialise, l'exploitation ne peut être qu'intensive et de grandes quantités de fourrages sont nécessaires pour équilibrer l'alimentation qui peut ne pas être exclusivement constituée d'aliments concentrés.
Dans les zones où existe du bétail laitier, la possibilité de produire des fourrages verts à contre-saison prend une importance considérable pour l'augmentation de la productivité et surtout le maintien des lactations en saison sèche.

Les sorghos paraissent réunir tous ces avantages avec en outre celui de pouvoir être utilisés dans l'alimentation humaine, comme il est de politique courante actuellement dans le sud de Madagascar.

\section{BUT DES ESSAIS}

Dans le cadre de l'étude de l'amélioration de l'alimentation du bétail, nous avons expérimenté des sorghos fourragers afin de préciser, dans les conditions propres à Madagascar:

- leur comportement;

- leurs besoins en eau;

- leur productivité et leur mode d'exploitation.

L'expérimentation a été orientée essentiellement :

1. Vers la production de fourrages de saison sèche. 
2. Vers l'accroissement des rendements annuels à l'hectare.

- D'après les exigences en eau des sorghos étudiées dans de nombreuses zones sèches des U.S.A., d'Italie, de France et d'Afrique du Sud, on pouvait penser a priori que $100 \mathrm{~mm}$ de pluies seraient suffisants pour provoquer la levée et produire un cycle végétatif complet. Si ce fait était confirmé par l'expérience, dans l'écologie particulière de l'Ouest et du MoyenOuest malgache, il serait possible de faire une culture de maïs, (cette plante étant la mieux adaptée pour fournir un fourrage abondant) pendant la première partie de la saison des pluies, et à contre-saison une culture de sorgho. Dans ce cas, on exploiterait au maximum les potentialités des terres hautes et on prolongerait en saison sèche la récolte de fourrages verts.

- A côté des zones d'élevage extensif existent des terres riches, alluvionnées chaque année par les crues (les baibo) et qui, après le retrait des eaux, peuvent être cultivées en saison sèche du fait de la persistance, à une faible profondeur, de la nappe phréatique. Actuellement, une partie des surfaces disponibles supporte des cultures industrielles (tabac, coton, arachide). Dans le cas de leur utilisation pour la production intensive de fourrages, le sorgho pourrait y remplacer le maïs qui, bien que produisant plus de grains secs à l'hectare, ne donne qu'une seule récolte.

- Il faut remarquer, que le sorgho, comme le maïs, présente un grand intérêt dans la mesure où l'on récolte la plante entière, au stade des grains pâteux, ou secs. Ce mode d'exploitation permet de produire plus d'unités fourragères à l'hectare pendant une période donnée qu'avec les graminées à haut rendement du genre Pennisetum qu'il n'est pas économique d'installer si le pâturage ne doit être que temporaire (cas de baibo).

\section{LES SORGHOS FOURRAGERS}

Les sorghos expérimentés ont été :

- des Sudan-grass,

- des hybrides ou Sudax, tous originaires des U.S.A.

Les semis sont effectués en lignes, les graines enfouies à $2,5 \mathrm{~cm}$ et les doses de semences sont d'environ $20 \mathrm{~kg} / \mathrm{ha}$.

Les moyennes des longueurs des cycles végétatifs sont à Madagascar de :

\begin{tabular}{|l|c|c|}
\hline & 1we coupe & 2 coupe \\
\hline Sudax & $54 \mathbf{j}$. & $43 \mathbf{j}$. \\
Sudan-grass & $93 \mathbf{j}$. & $74 \mathbf{j}$. \\
\hline
\end{tabular}

On a remarqué que les coupes répétées favorisaient le taillage, et que, si en pays tempéré après la première coupe les talles ne produisaient pas de grains, en milieu tropical tous les talles nouveaux fructifiaient. Mais la fructification est échelonnée sur les divers pieds, et sur un même pied, ce qui empêche d'obtenir une récolte homogène.

\section{PRODUCTION FOURRAGERE EXPERIMENTATIONS}

\section{A. Etude des possibilités d'utilisation}

L'intérêt des sorghos résidant essentiellement dans leur résistance à la sécheresse, une étude de leurs exigences en eau et de l'influence des pluies sur les rendements a été effectuée en fin de saison des pluies. On a étudié en saison sèche, afin d'éviter toute erreur due à une pluie isolée, les quantités d'eau nécessaires à la levée.

\section{Quantité d'eau minimale nécessaire à la levée}

Au Centre de Recherches zootechniques de Miadana, sur sols sablonneux, en pleine saison sèche, deux parcelles ensemencées le 29 mai 1967 ont été irriguées de telle façon que les quantités d'eau utilisées représentent l'équivalent de $100 \mathrm{~mm}$ de pluies pendant 20 jours. Deux coupes ont donné respectivement :

Le 22 août . . . . . . . 13,5 t/ha

Le 15 novembre . . . . . . 10,6 t/ha

Soit un total de . . . . . 24,1 t/ha

2. Quantité d'eau minimale nécessaire pour une récolte normale

Sur le même terrain, deux parcelles ensemencées à la même date ont été irriguées pendant toute la saison sèche. Les quantités d'eau utilisées peuvent être considérées comme des 
minimums, le rythme des irrigations étant établi d'après l'apparition des signes de flétrissement.

Les rendements obtenus sont de:

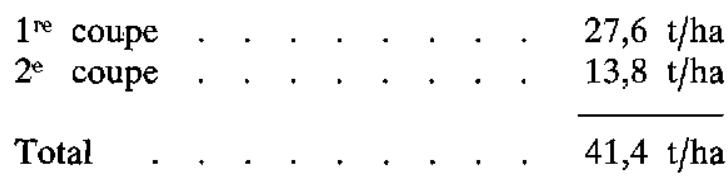

pour une quantité d'eau globale de l'ordre de $2.600 \mathrm{~m}^{3} / \mathrm{ha}$.

On admet, aux U.S.A. qu'il faut environ $2.800 \mathrm{~m}^{3} /$ ha pour une récolte normale de 40 t/ha. HUGUES, cite, qu'à Akron, au Colorado, SHANTS et PIEMIESEL ont mis en évidence un taux de consommation en eau moyen de $274 \mathrm{l} / \mathrm{kg}$ de matière sèche produit.

A Madagascar, nous avons obtenu un taux de consommation de l'ordre de $264 \mathrm{l} / \mathrm{kg}$ de matière sèche.

On peut conclure de cette première expérimentation que, dans les conditions locales où nous avons opéré :

1. $100 \mathrm{~mm}$ d'eau suffisent pour assurer la levée des sorghos;

2. la quantité d'eau nécessaire en saison sèche pour une récolte normale (40 t/ha) est de l'ordre de $2.600 \mathrm{~m}^{3} / \mathrm{ha}$.

Ces deux résultats expriment l'adaptation du sorgho à la sécheresse, et nous ont amené à étudier les possibilités de leur culture dans des conditions particulières d'approvisionnement en eau :

- en fin de saison des pluies (semis échelonnés);

- en culture dérobée derrière le maïs;

- sur terres de décrue en saison sèche (approvisionnement à partir de la nappe phréatique).

\section{B. Utilisation des sorghos fourragers}

\section{En saison sèche (1968)}

En tenant compte de la pluviométrie moyenne de la zone considérée $(1.200 \mathrm{~mm})$ et des résultats précédents, nous avons effectué, à Miadana des semis échelonnés entre le 15 mars et le 10 avril, période pendant laquelle l'observation montre qu'il tombe habituellement environ $100 \mathrm{~mm}$ de pluies.

Les sols sont sablonneux. Une fumure organique de $20 \mathrm{t} / \mathrm{ha}$ a été utilisée (fumier de fosse).
Les résultats sont rapportés sur les graphiques I et II.

Le graphique $n^{\circ} I$ indique la hauteur et la fréquence des pluies qui ont suivi les semis. On remarque que si les deux premières parcelles semées le 15 et 23 mars ont des rendements sensiblement égaux en première coupe, c'est qu'elles ont reçu la même quantité d'eau (143,3 et $141,8 \mathrm{~mm}$ ) dans les 20 jours qui ont suivi les semis. Par contre, les parcelles suivantes semées le $1^{\text {rr }}$ et 10 avril ont bénéficié de quantités d'eau différentes, et surtout inégalement réparties.

La parcelle qui n'a pratiquement pas eu de pluies pendant la période critique de 20 jours après le semis, bien qu'ayant un rendement satisfaisant en première coupe, est celle qui a la production la plus basse sur l'ensemble des 3 coupes (voir graphique $n^{0}$ II).

Pour obtenir une production de fourrages suffisante, il faut donc que les sorghos bénéficient d'au moins $100 \mathrm{~mm}$ de pluies dans les 20 jours qui séparent les semis de la levée.

\section{Production annuelle avec et sans irrigation}

Après avoir exploité les deux coupes de saison sèche, les premières parcelles ayant permis l'étude des besoins minimaux en eau ont été conservées afin de permettre l'étude de l'évolution de la plante sur une année entière, et de juger de l'épuisement des sols.

En zone tempérée, la plante est exploitée en été, et après deux coupes elle disparaît parce qu'elle est éliminée par le froid de l'hiver. Ce qui est remarquable, c'est qu'en zone tropicale, la fin de culture à contre saison coïncide avec le début des pluies, et que les sorghos ont continué à produire et ont même atteint un maximum au début des pluies, alors que l'irrigation était arrêtée depuis le 26 septembre.

Ce fait est important à noter parce qu'il montre que dans une exploitation, où l'on cultiverait les sorghos pour produire du fourrage en saison sèche, on pourrait maintenir les cultures pendant la saison des pluies jusqu'à la date des semis à contre saison suivants.

Les coupes faites en deuxième année après le mois de mars (époque des semis) ne représentent pas plus de 18 p. 100 de la production annuelle totale et on a intérêt à recommencer une culture. 


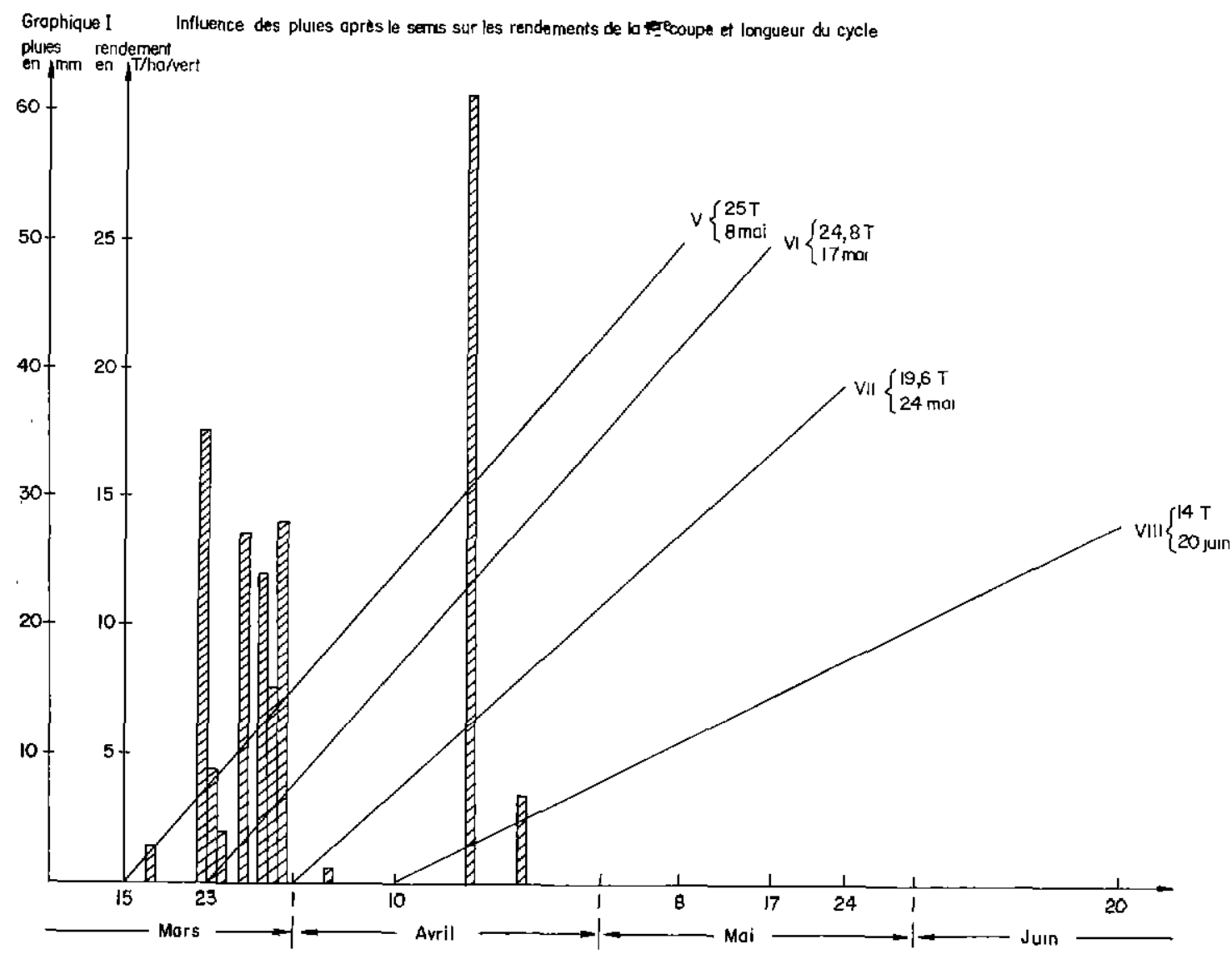

Sans fertilisation d'entretien, l'épuisement des souches'a été progressif, comme l'indique le graphique $\mathrm{n}^{\circ}$ III mais il est certain qu'à partir de la $5^{\text {e }}$ coupe (7 juin 1968) c'est-à-dire, à la fin de la saison des pluies qui suit le semis de saison sèche, il n'y a aucun intérêt à conserver la plantation, si ce n'est pour maintenir une couverture du sol.

\section{En culture dérobée derrière le mä̈s}

Dans le Moyen-Ouest, où la pluviométrie est plus élevée $(1.650 \mathrm{~mm})$, il est possible de récolter le maïs avant l'arrêt des pluies. Une culture dérobée de sorgho est donc possible et doit permettre de récolter sur un même terrain, soit :

- 2 récoltes de grains (maïs + sorgho);

- 1 récolte de grains et une récolte de fourrage vert (ou l'inverse);

- 1 récolte de fourrage vert suivie d'une réserve de fourrages sur pied.
Selon que les conditions climatiques seraient favorables ou non.

Les parcelles (10 avec une répétition soit 20 au total) ont reçu une fumure optimale: Fumier animal . . . . . . 40 t/ha Scories de déphosphoration . 1,2 t/ha CIK . . . . . . . . . $750 \mathrm{~kg} / \mathrm{ha}$ Dolomie . . . . . . . $500 \mathrm{~kg} / \mathrm{ha}$ Urée . . . . . . . . . $250 \mathrm{~kg} / \mathrm{ha}$

Il est certain que de telles fumures ne peuvent être étendues en milieu paysan, mais le but poursuivi, était, essentiellement, d'estimer l'évaluation des potentialités maximales des sols riches, en culture intensive de type industriel.

Le maïs a été semé le 15 novembre.

Les différents objets étaient les suivants:

A. Maïs récolté en grains + , sorgho coupé au stade grains pâteux. 


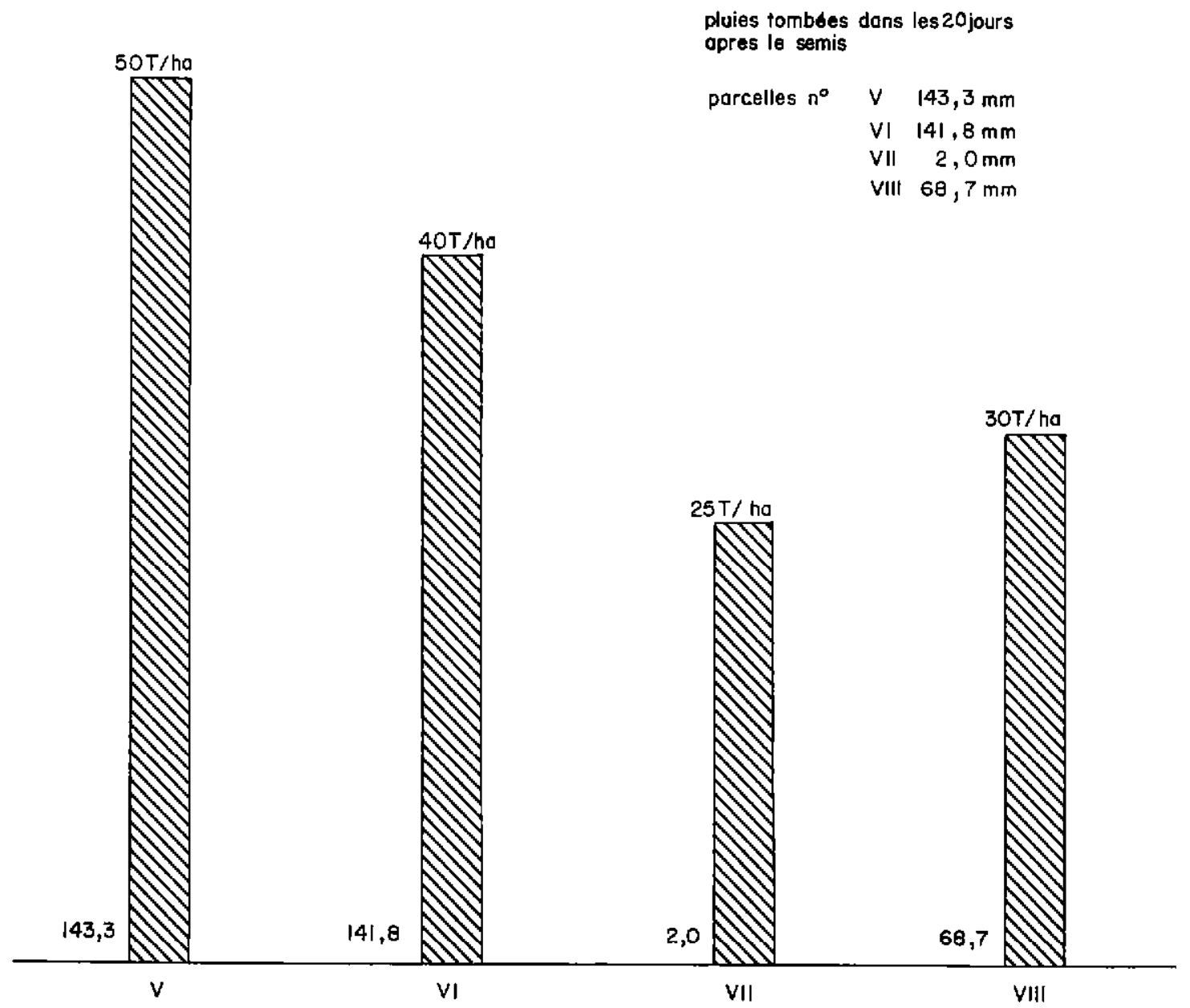

B.' Maïs récolté en grains + sorgho coupé en vert (à $80 \mathrm{~cm}$ de hauteur).

C. Maïs récolté en grains + sorgho laissé en défens en saison sèche et exploité au début des pluies (hypothèse défavorable dans le cas où les pluies seraient insuffisantes).

D. Maïs récolté en vert (à $100 \mathrm{~cm}$ de hauteur) + sorgho coupé au stade "grains pâtéux $n$.

E. Sorgho seul (témoin).

\section{Résultats}

Objet $E$

En saison des pluies, les sorghos sont éliminés par un parasitisme intense. Leur vocation semble être la culture dérobée ou à contre saison.
Objet $A$

Production d'UF/ha

Maïs à grains . . . . . , $11.200 \mathrm{UF}$

Sorghos ensilage . . . . $1.050 \mathrm{UF}$

12.250 UF

Objet $B$

Production d'UF/ha

Maïs à grains . . . . . . $11.200 \mathrm{UF}$

Sorghos en vert . . . . . $1.500 \mathrm{UF}$

Objet $C$

12.700 UF

Sorghos non exploités.

Objet $D$

Production d'UF/ha 


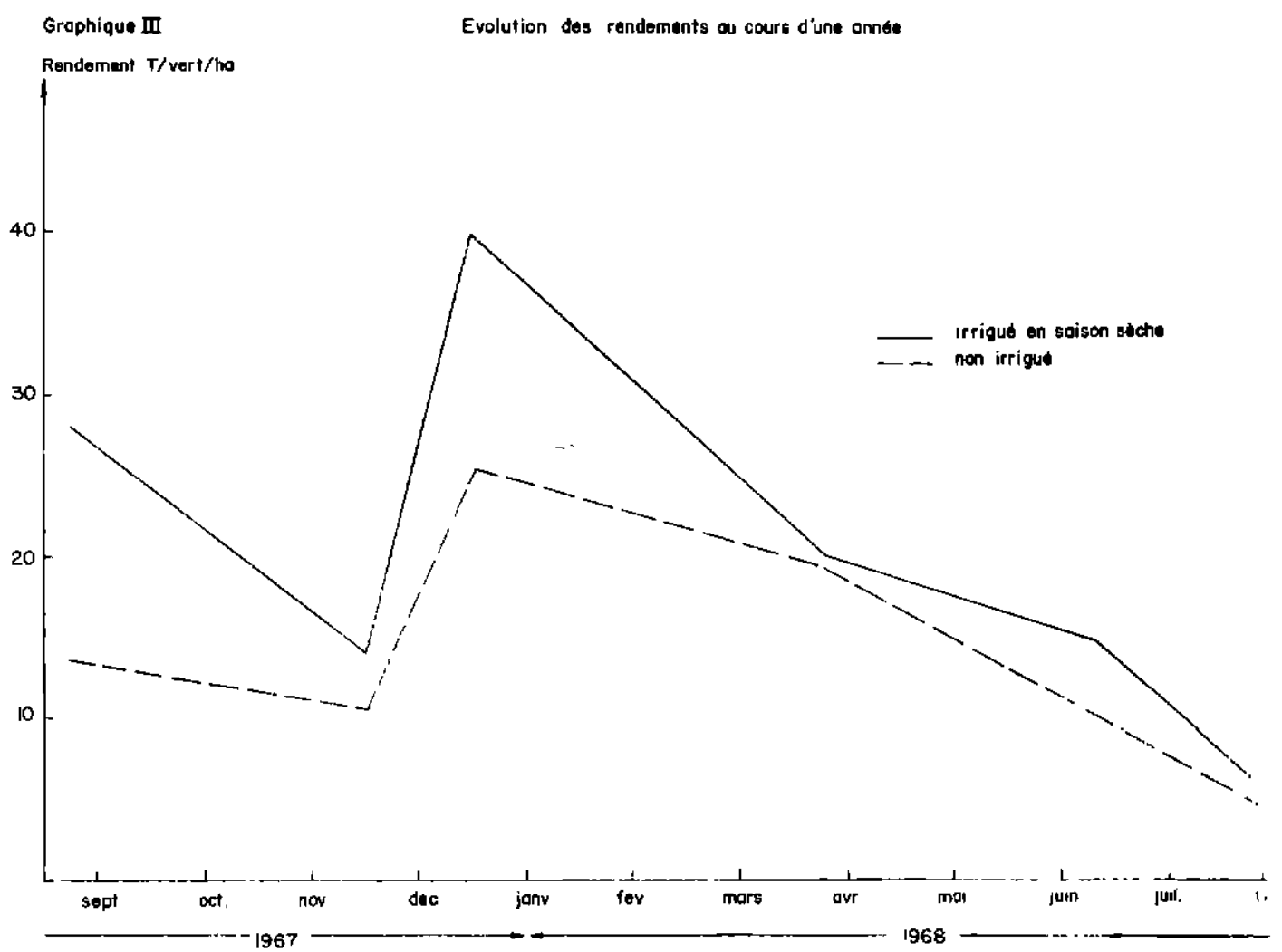

Maïs ensilage . . . . . $3.400 \mathrm{UF}$ Sorgho ensilage . . . . . . $3.250 \mathrm{UF}$

$6.650 \mathrm{UF}$

Discussion

- Il est possible de faire une culture dérobée de sorgho après le maïs sur une même parcelle, en fin de saison des pluies.

- Dans la production d'UF, le maïs grains représente l'apport le plus important. Il ne devrait être ensilé que dans le cas où une climatologie défavorable ou un parasitisme risquent de compromettre la fructification.

- Le sorgho peut être utilisé en vert ou sous forme d'ensilage selon qu'il doit être exploité au début ou à la fin de la saison sèche.

- L'intensification des productions exige l'emploi de fumures d'entretien à des doses élevées, mais celles-ci sont rentabilisées par l'augmentation des rendements du maïs.

Introduction d'une culture dérobée de sorgho dans l'assolement
La culture du sorgho a été expérimentée dans le cadre d'une étude particulière intitulée "Intégration du pâturage artificiel dans l'assolement ».

Le but de cette étude était de montrer l'intérêt de l'introduction d'une sole fourragère de Stylosanthes gracilis, et son influence sur la charge à l'hectare, l'évolution des sols, et l'augmentation des rendements des cultures en tête d'assolement.

Un pâturage de Stylosanthes de 3 ans a été labouré en fin de saison sèche et après application de la fumure suivante:

Scories de déphosphoration . . $1.000 \mathrm{~kg} / \mathrm{ha}$ Chlorure de potasse . . . . $600 \mathrm{~kg} / \mathrm{ha}$ Carbonate de calcium et de magnésium . . . . . . $400 \mathrm{~kg} / \mathrm{ha}$

On a fait une culture de maïs (plante de rente venant en tête de l'assolement).

L'enrichissement du sol par le Stylosanthes a permis de faire une coupe précoce (le 21 décembre) du maïs pour ensilage $(33,7 \mathrm{t} / \mathrm{ha}$ en vert) et de faire une culture dérobée de sorgho 
(Sudax E 56) qui, exploitée en grains secs le 27 avril, a donné une récolte de 3,17 t/ha.

La production d'UF à l'hectare, qui correspond au mode d'exploitation des objets $D$ de l'expérimentation précédente a été dans ce cas de $7.700 \mathrm{UF} / \mathrm{ha}$ environ.

\section{Culture à contre-saison sur terres alluvionnées (embouche industrielle)}

A la suite d'une étude sur les possibilités d'embouche, des essais de sorghos ont été effectués sur les terrains retenus par le projet pour la mise en place d'une unité d'embouche industrielle à Anjiajia (Province de Majunga).

Le but de ces essais est de préciser la productivité des sorghos, le mode d'exploitation et leur valeur fourragère, et éventuellement d'étudier leur substitution à la culture traditionnelle du maïs.

\section{Le milieu}

Les sols sont alluvionnés tous les ans par les débordements de la rivière Kamoro. Ce sont des limons argilo-sableux, bien minéralisés mais moyennement pourvus en matière organique. Ils sont relativement homogènes. On $y$ trouve un horizon sablonneux entre 30 et $80 \mathrm{~cm}$ de profondeur.

La végétation est approvisionnée en eau uniquement par les remontées par capillarité à partir de la nappe phréatique dont les variations de niveau sont indiquées dans le graphique $\mathrm{n}^{0}$ IV. Malgré la profondeur de cette nappe, la structure de sols permet aux racines de pénétrer dans la couche fraîche et d'atteindre le niveau supérieur de la remontée capillaire. A aucun moment, tout au long de la saison sèche, on n'a observé des signes de flétrissement des feuilles.

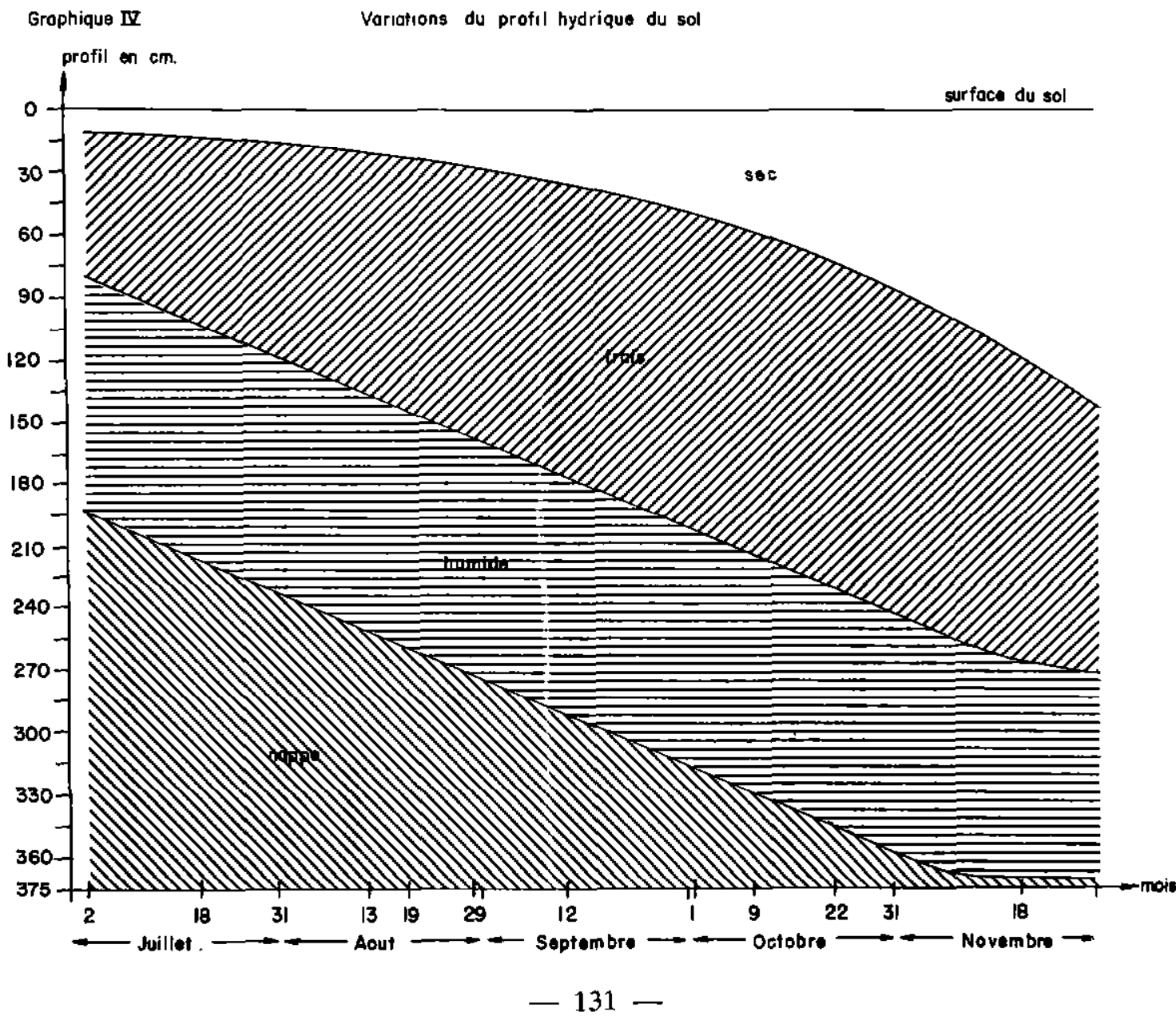




\section{Les impératifs culturaux}

Etant donné la situation de ces terrains à proximité des fleuves, la saison des cultures est limitée :

- par le drainage en surface des sols en fin de saison des pluies;

- par les risques de submersion en fin de saison sèche.

Afin d'exploiter au maximum les réserves en eau, il est impératif de préparer les sols le plus tôt possible, dès que l'on peut pénétrer avec un engin sans risquer de s'enliser.

En 1969, les semis échelonnés ont montré qu'il n'était pas mécaniquement possible de préparer le sol avant la fin avril, son humidité empêchant tout affinage en surface. D'autre part, les semis du 29 mai ont donné une deuxième coupe en fin novembre ce qui est une date limite, la zone ayant été submergée au début de décembre.

Les semis doivent donc être effectués entre la fin avril et la fin mai. On dispose d'un mois pour échelonner les semis afin d'étaler la production.

\section{Protocole expérimental}

L'expérimentation prévoyait des semis échelonnés tous les 10 jours pendant la période favorable, le contrôle des coupes des rendements en vert et en matière sèche, du pourcentage de grains, de la valeur fourragère et des teneurs en carotènes. 5 semis ont pu être faits entre le 18 avril et le 29 mai.

\section{Résultats}

a) Durée des cycles (graphique $\mathrm{n}^{\circ} \mathrm{V}$ )

Les moyennes dont de:

- $1^{\text {re }}$ coupe : 93 jours soit 3 mois;

- $2^{\mathrm{e}}$ coupe : 73,6 jours soit 2 mois $1 / 2$.

Soit une durée totale de 5 mois $1 / 2$, pour une période d'exploitation étalée du 18 juillet au 18 novembre soit 4 mois en pleine saison sèche.

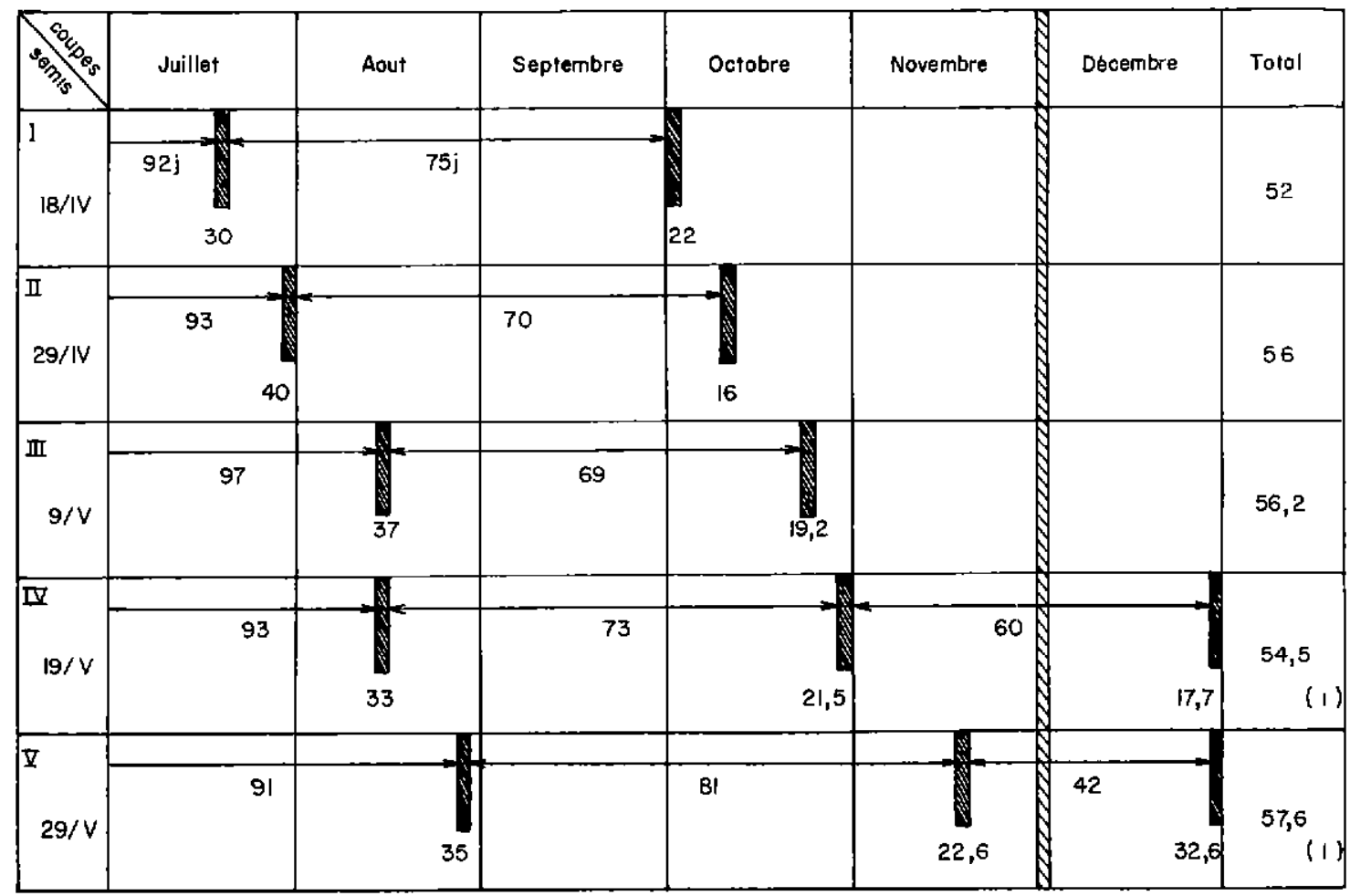

(1) on ne tient pas compte des coupes de Décembre, inexploitobles meconiquement 


\section{b) Les rendements (graphique $\mathrm{n}^{\circ} \mathrm{V}$ )}

Les coupes ont été effectuées à partir du stade " grains pâteux " jusqu'au stade " grains secs".

On obtient les moyennes suivantes:

$\begin{array}{llllllll}1^{\mathrm{re}} \text { coupe } & . & . & . & . & . & 35 \mathrm{t} / \mathrm{ha} \text { en vert } \\ 2^{\mathrm{e}} \text { coupe } & . & . & . & . & . & 20,2 \mathrm{t} / \mathrm{ha} \text { en vert }\end{array}$

Total . . . . . 55,2 t/ha en vert

La production de matière sèche ne peut être calculée qu'approximativement par suite de la non synchronisation de la maturation des graines dans une même parcelle.

Elle est d'environ:

$$
\begin{aligned}
& 1^{\text {re }} \text { coupe }: \frac{35 \mathrm{t} \times 25}{100}=8,75 \mathrm{t} \\
& 2^{\mathrm{e}} \text { coupe }: \frac{20,2 \mathrm{t} \times 30}{100}=6,06 \mathrm{t}
\end{aligned}
$$

Total . . . . . . . $=14,8 \mathrm{t} / \mathrm{ha}$
Soit une production d'U.F. d'environ

$$
\begin{array}{r}
(8.750 \times 0,85)+(6.000 \times 0,80) \\
\text { \# } 12.230 \mathrm{UF} / \mathrm{ha}
\end{array}
$$

Il faut noter que des pluies tombées en novembre ont permis aux parcelles IV et $\mathrm{V}$ qui venaient d'être fauchées, de faire un troisième cycle. Les parcelles I, II, III s'étaient épuisées avant les pluies et n'ont pas repoussé. Il n'est pas possible de tenir compte de ces coupes de décembre, les sols ayant déjà été submergés, ce qui interdit toute exploitation mécanique.

Mais la submersion à cette époque étant de courte durée, il peut être possible de faire pâturer le $3^{\prime \prime}$ cycle avant que les crues de janvier interdisent tout accès au bétail.

Le tableau $n^{\circ} I$ indique les pourcentages du poids des panicules sur le rendement global. Il est de l'ordre de 10 p. 100 , ce qui donne une production de grains de l'ordre de $5 \mathrm{t} / \mathrm{ha}$ (grains + panicules).

TABLEAU $N^{\circ} I$

Rendements en grains

\begin{tabular}{|l|c|c|c|c|}
\hline & I & II & III & IV \\
\hline Rendement global/Ha en tonres & 22 & 16 & 37 & 21,5 \\
\hline Rendement en panicules T/Ha & 2,0 & 1,6 & 4,1 & 1,53 \\
\hline $\begin{array}{l}\text { Pourcentage de panicules sur } \\
\text { le rendement global }\end{array}$ & 9,5 & 10 & 11 & 7,1 \\
\hline
\end{tabular}

\section{c) Bromatologie}

Des analyses systématiques à chaque coupe ont permis de dresser le tableau $n^{0}$ II.

On voit que la matière sèhe évolue de 25 à 36 p. 100 essentiellement, et que si les teneurs en sels minéraux, lipides et matières azotées sont relativement stables, les teneurs en cellulose diminuent au fur et à mesure de la formation des grains, ce qui augmente la valeur fourragère de la plante entière.

Les teneurs en calcium et surtout en phosphore sont bonnes pour un fourrage tropical cultivé sans engrais.
Les teneurs en carotènes sont suffisantes pour couvrir les besoins du bétail en vitamine $\mathrm{A}$.

On peut remarquer que les compositions du fourrage en calcium et phosphore sont le reflet des teneurs des sols en ces éléments. Les terres de décrue se caractérisent par leur richesse en calcium et une légère insuffisance en phosphore.

La valeur fourragère calculée d'après les “Tables Hollandaises " est élevée à cause de la teneur importante en extractif non azoté (supérieure à 55 p. 100) due à la présence des grains. 
TABLEAU $N^{\circ}$ II

Bromatologie

\begin{tabular}{|c|c|c|c|c|c|c|c|c|c|c|c|}
\hline \multirow[b]{3}{*}{ Dëtermination $\mathrm{N}^{\circ}$ échantilion } & \multicolumn{8}{|c|}{ lère coupe } & \multicolumn{3}{|c|}{ 2ème coupe } \\
\hline & \multicolumn{5}{|c|}{ Grains pâteux } & \multicolumn{3}{|c|}{ Grains secs } & \multicolumn{3}{|c|}{ Grains secs } \\
\hline & 349 & 347 & 310 & 350 & 311 & 337 & 336 & 348 & 391 & 370 & 371 \\
\hline Matières gèches & 22,1 & 24,2 & 25,2 & 25,5 & 26,8 & 30 & 36 & 36 & 28,7 & 33,2 & 36,3 \\
\hline Matières minërales & 10 & 8,8 & 8,2 & 12,6 & 9,7 & 10,2 & 9,1 & 7,7 & 14,3 & 8,2 & 10,8 \\
\hline Matières grasses & 2 & 2,6 & 2,2 & 2,6 & 2,9 & 2,8 & 2,9 & 3,1 & 1,7 & 1,7 & 1,8 \\
\hline Matières azotées & 7,7 & 10,6 & 7,8 & 6.6 & 8,8 & 7,4 & 8,9 & 9,2 & 7,7 & 5,5 & 6,1 \\
\hline Cellulose & 26,6 & 25,6 & 27,2 & 26,9 & 22,1 & $.18,2$ & 16,9 & 16,3 & 23,7 & 23,5 & 25,5 \\
\hline Extractif non azoté & 53,5 & 52,1 & 54,4 & 51,1 & 56,3 & 61,2 & 62 & 63,5 & 52,4 & 60,9 & 55,6 \\
\hline Insoluble chlorhydrique & 5.7 & 4,6 & 4,0 & 8,5 & 5,6 & 5,9 & 5,5 & 4,7 & 5,1 & 5,0 & 7,0 \\
\hline Phosphore & 0,2 & 0,26 & 0,24 & 0,20 & 0,24 & 0,21 & 0,24 & 0,26 & 0,20 & 0,18 & 0,18 \\
\hline Calcium & 0,28 & 0,25 & 0,19 & 0,33 & 0,22 & 0,32 & 0,30 & 0,19 & 0.22 & 0,30 & 0,20 \\
\hline Caratènes mg $/ \mathrm{kg}$ sur sec & - & 186 & 91 & - & 77 & - & - & 75 & 222 & 69 & 168 \\
\hline $\mathrm{UF} / \mathrm{kg} / \mathrm{m} . \mathrm{s}$ & 0,77 & 0,81 & 0,78 & 0,71 & 0,87 & 0,95 & 0,98 & 1 & 0,76 & 0.87 & 0,78 \\
\hline $\mathrm{UF} / \mathrm{kg}$ brut & 0,16 & 0,19 & 0,19 & 0,18 & 0,23 & 0,28 & 0,35 & 0,36 & 0,21 & 0,28 & 0,28 \\
\hline
\end{tabular}


Le graphique $\mathrm{n}^{\circ}$ VI montre l'évolution de la valeur fourragère en fonction de la richesse en matière sèche, donc de la maturation et de la diminution du taux de cellulose.

\section{Utilisation}

Il ressort de cette étude que les sorghos, sur terres alluvionnées, cultivés en saison sèche, présentent un intérêt économique supérieur au maïs pour les raisons suivantes :

- production d'UF supérieure;

- étalement de la production ce qui :

- facilite la gestion,

- permet de réduire le matériel pour la récolte;

- meilleure utilisation des disponibilités en eau;
- disponibilités en fourrages sur pied jusqu'à la saison des pluies.

Un inconvénient réside dans la nécessité d'importer les semences dans l'immédiat.

Le sorgho peut être utilisé en vert ou ensilé. L'ensilage de la deuxième coupe permettrait d'alimenter le bétail jusqu'à ce que l'on puisse exploiter les fourrages cultivés en saison des pluies sur les terres hautes (maïs, Pennisetum purpureum).

\section{CONCLUSION}

Les expérimentations effectuées à Madagascar permettent d'affirmer que :

- Les sorghos donnent de bons résultats dans le cas d'une culture dérobée ou à contre-

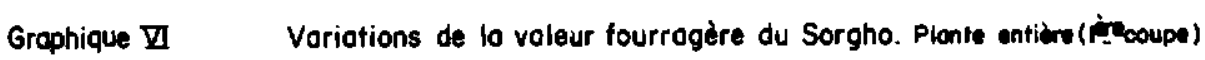

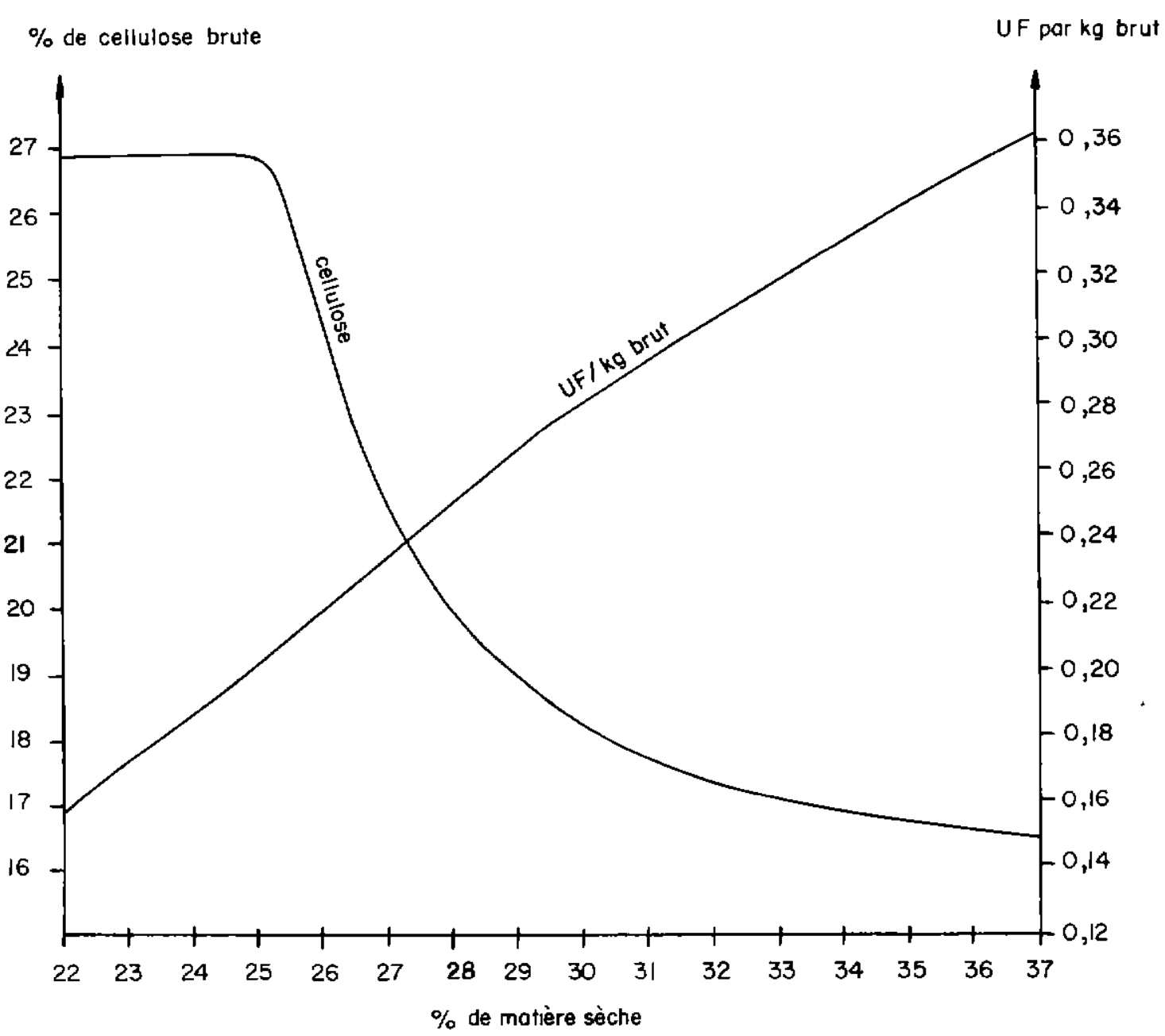


saison grâce à leurs faibles exigences en eau.

- Ils répondent bien à l'irrigation et peuvent exploiter les potentialités élevées des terres alluviales dans le cadre d'une embouche industrielle.

- Les cycles du maïs et du sorgho peuvent, dans certain cas, permettre une double culture sur la même parcelle.

Dans la mesure où l'on peut maintenir une fertilisation d'entretien, l'introduction des sorghos hybrides dans l'exploitation fourragère devrait faciliter l'intensification de l'élevage. II est possible d'envisager l'embouche en feed-lot en milieu tropical comme elle est pratiquée dans les zones sèches des U.S.A., la ration comprenant la distribution de fourrages ensilés (maïs et sorgho) et des sous-produits tels que les farines basses de riz, et les tourteaux de coton.

Dans la région où la vocation est l'élevage semi-intensif ou intensif intégré à l'agriculture comme le Moyen-Ouest, les sorghos amélioreraient l'alimentation des vaches laitières avec un apport de matières azotées, d'énergie, et de carotènes en saison sèche.

\title{
SUMMARY
}

\section{Sorghum forage growing in Madagascar}

The experiments which the authors undertook showed the interest by the Sorghums, as much as catch-crops, as as off season crops.

Their low water requirements and their high yield will allow a better use of soils, an intensification of cattle production (beef and milk), and where by-products such as rice polishings and oil-cakes are available, the fattening of animals such as are required by the Malagasy cattle commercial circuits and butchery.

\section{RESUMEN}

EI cultivo de los sorgos forrageros en Madagasear. Utilización fuera de la estación

\begin{abstract}
Los ensayos efectuados por los autores comprobaron el interés de los sorgos en cultivo intermedio como en cultivo fuera de la estación. La exigencia mediana de agua y el rendimiento importante de los dichos tienen que permitir una mejora utilización de los suelos, el intensificar de la ganaderia (came y leche) $y$, en todas partes donde existen subproductos como las harinas de arroz y las tortas, la producción de animales de engorde como los necesitados por el comercio del ganado y la carniceria malgacha.
\end{abstract}

\section{BIBLIOGRAPHIE}

CASABIANCA (F., de), « Abord agronomique des baibos du Nord-Ouest de Madagascar », Rapport IRAM Madagascar.

GRANIER (P.), «Intégration du pâturage artificiel dans l'assolement (Moyen-Ouest), Madagascar», Tananarive, I.E.M.V.T., 1968.

GRANIER (P.), «Les possibilités d'embouche intensive à Madagascar, Colloque OCAM sur l'Elevage, Fort-Lamy, 8-13 déc. 1969.
HUGUES (P.), "Les sorghos fourragers ", Fourrages, 1966 (27): 71-107; (28): 107-161; (30): 56-140.

RAZAKABOANA (F.), \& Les cultures fourragères en baibo ", Madagascar, Rapport IRAM, nov. 1967.

SARNIGUET (J.), TYC (J.), GRANIER (P.), PEYREDIEU du CHARLAT (F.), «Etude du Projet d'Anjiajia - Majunga. Réalisation d'un centre d'embouche intensive et d'un abattoir frigorifique d'exportation », Paris, Maisons-Alfort, SEDES, I.E.M.V.T., 1969. 